\title{
4 Championing Empathy
}

\author{
Csilla E. Ariese
}

\begin{abstract}
Empathic behavior is all the more important in a globalizing world and to tackle the current problems facing our globe. Although emotions have not always been the strong suit of museums, in recent years emotive exhibitions have become more common, as well as creating space for emotional experiences, reflections, and social interactions. Museums are well-equipped to support championing empathy and to encourage empathic behavior among their visitors. They can challenge harmful stereotypes. Furthermore, empathy is also an important skill honed 'back stage' in museums, in terms of HR policies, equitable hiring, broad representation, and balanced management.
\end{abstract}

Keywords: emotive exhibitions, equity, staff representativity, challenging stereotypes

Empathy for other living beings is the key to better and more

generous behavior.

\section{The challenge}

Empathy is the ability to understand and share in the emotions of another being. Some people are naturally more empathic than others; learning to be (more) empathic is vitally important. In an increasingly populated and globalizing world, it is tempting to group humans and other living beings in big clusters of anonymity. Stereotyping is one way in which this is achieved: "men are bad at multi-tasking" or "cats are aloof and dogs are loving." Beyond being a source of error and (hurtful or harmful) discrimination, stereotyping also provides distance. Being able to dismiss a whole group of people due

Ariese, Csilla E., and Magdalena Wróblewska, Practicing Decoloniality in Museums: A Guide with Global Examples. Amsterdam, Amsterdam University Press 2022 DOI: $10.5117 / 9789463726962 \_C H O 4$ 
to some (perceived) quality allows for a false disconnect between yourself and them, effectively 'othering' them and making them unrelatable.

Yet, in a globalizing world, empathy for others, and particularly for those whom we might perceive to be 'different,' is all the more important to tackle the challenges of our era: the climate crisis, migration, pandemics, and so on. These challenges force us to work together globally and bring us into contact with other people around the world. If we are unable to feel empathy for others, we will be unable to work together or unwilling to help each other. Selfishness is the result of a lack of empathy.

Museums have a role to play in championing empathy when it comes to their staff, visitors, and partners. Yet if museums do not lead by example internally, the empathic tone of an exhibition or program may feel disingenuous or hypocritical - for instance, if the museum is very careful to use certain terminology to make a community feel respected, but then does not offer staff members from that community fair wages or the same respectful tone in the work environment. Championing empathy is a task that needs to be undertaken behind the scenes as well as in the public arena.

Over the last couple of decades, museums have become more familiar with emotive exhibitions which build on emotional storytelling devices. Such exhibitions may feature quotes or personal narratives, thus highlighting individual biographies rather than generalizing. Such techniques work because visitors can more easily connect to a named individual than to an anonymous group, and building empathy for such a non-anonymous person can in turn create empathy for the community they belong to. Personal narratives are relatable, and being able to relate to someone is an important step in coexisting and cooperating.

Museums have also been making use of more interactive displays (whether digital or analogue) and this creates opportunities for visitors to engage and interact with others - whether from the same visiting group or with strangers. At the Anne Frank House (starting in 2005) Free2Choose was an interactive display ${ }^{1}$ which showed a series of film clips on conflicting rights and freedoms guaranteed by law: what if neo-Nazis use the right to demonstrate in front of a synagogue on Sabbath? Visitors were prompted at the end of each clip with a question and a yes or no vote. The results of the current visitors' vote, plus the overall results from all past visitors, would be immediately shown and were used by museum educators to ignite deep, critical conversations. By tying into the biography of Anne Frank and tool. 
her family, visitors could relate to the issues more empathically as well as understand that not all questions have simple answers.

\section{The change}

Championing empathy is essentially an individual process, which might make it seem like institutions do not have a role to play in increasing empathy. Yet, as institutions which guide behavior, provide knowledge, and allow space for emotions, museums are well positioned to champion empathy.

Above, I have already mentioned two examples. Interactive displays create opportunities for interaction with others and can be suitable for practicing and nurturing empathy. Emotive exhibitions using devices such as personal narratives can encourage visitors to relate to other persons or communities. Another type of emotive exhibition, which creates opportunities for experiencing and processing deep feelings, can also spark empathy. For these kinds of exhibitions, it is crucial to provide space for visitors to process or to safely discuss with others what they are feeling and experiencing.

Yet championing empathy goes deeper than exhibition practices and displays. It begins with the institutional mission and vision and the way in which staff members are treated within the museum: fair hiring and equal wages, transparent HR policies, an atmosphere in which everyone feels that they are respected and in which all are treated with dignity. Ensuring that staff is representative of target audiences is currently high on the agenda of museums, but if this 'diversity' is not present on all levels of staff/management, representation is limited and tokenistic. Additionally, diversity training may be necessary to discuss safe work environments. Terminology, phrasings, tone of voice, and behavior can all be worked on to ensure respect and sensitivity between staff. A better awareness of internal shortcomings, and the hard work needed to improve empathy within the museum, will also aid museum staff in their interactions with visitors.

Empathy is a skill that can be honed through museum visiting. Museum educators, and not just those working with children and young adults, are already very knowledgeable about training empathy and have vast experience in providing activities or moderating discussions that can support empathy. Museum guides are trained to bring strangers closer together during the course of a tour, finding points from which they can relate to each other and develop empathy. Museum staff working in front of house positions are also very familiar with treating visitors respectfully. However, 
for all museum staff it will remain a skill to practice daily to retain empathy and step beyond the simple stereotyping of visitors into categories.

Exhibitions can transparently challenge harmful and hurtful stereotypes, for instance by condemning issues such as discrimination (whether sexism, racism, homophobia, islamophobia, etc.), or supporting human and equal rights issues. As institutions that are often still seen as authoritative and which are trusted providers of information, museums can be greatly influential if they speak out sincerely. If a museum's decision is seen as very bold, it could lead not only to empathy, but also to decentering of the norm.

Although becoming more empathic is a personal process and challenge, museums can certainly play a role - on the one hand, by leading by example with their internal communication, policies, and interactions; on the other hand, by supporting and encouraging empathy within and between visitors.

\section{National Museum of African American History and Culture | Washington, D.C., USA}

Part of the Smithsonian Institution, the National Museum of African American History and Culture (NMAAHC) was opened to the public in $2016 .{ }^{2}$ Its development had taken 100 years of campaigning, since the first attempt for the creation of the museum by African American civil war veterans in 1916. The museum is dedicated to the documentation of African American life, history, and culture. It positions itself as a museum that shares an American story for all Americans, through an African American lens.

The creation of the NMAAHC was unique in the sense that the museum had no collections when the institution was formally established in 2003 . The museum decided to completely develop its own collections, rather than to take over previously existing collections housed in other institutions. A large portion of the staff was tasked in various ways to collect objects for the museum - both in the USA and from African nations and cultures. By the time of opening, the collection contained 34,000 items.

The diversity and depth of the collection is reflected in the museum's 12 exhibitions, spread out over five floors. Some of these exhibitions celebrate African American achievements, for instance in the arts or sports, or explore different contemporary communities. The history galleries are profoundly emotional and political spaces, where histories of slavery, resilience, wars, civil rights movements, emancipation, and segregation are unpacked. The history galleries combine the long arc of history with personalized narratives 
Figure 4.1 Contemplative Court

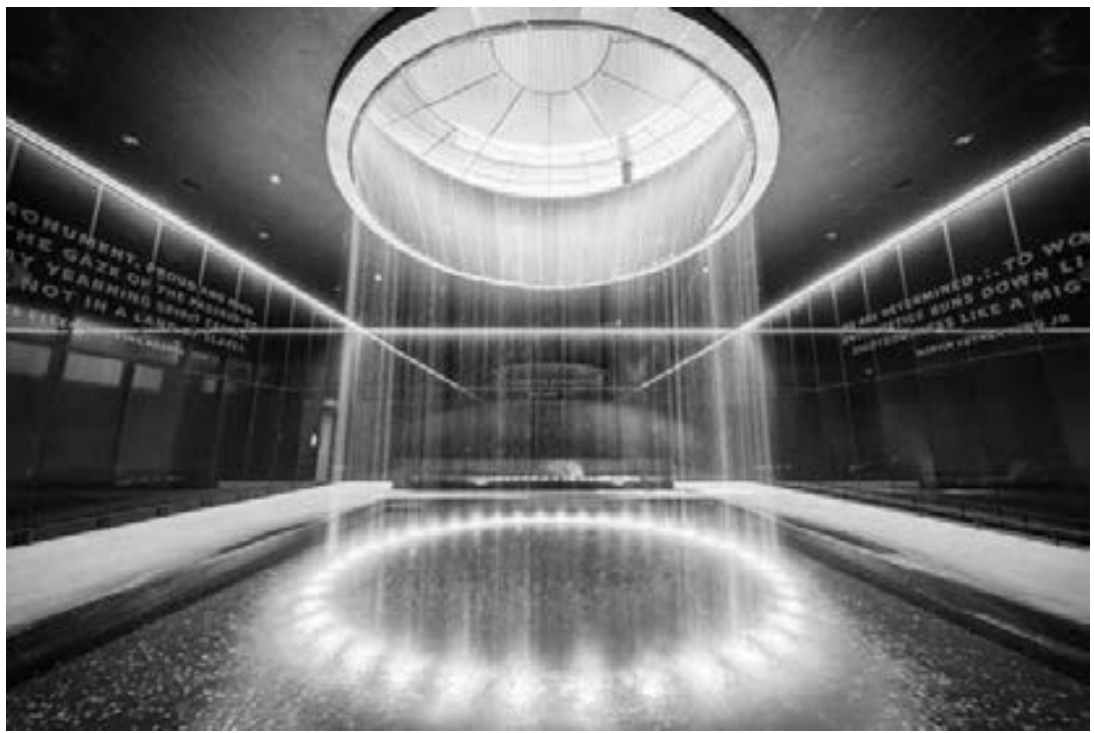

National Museum of African American History and Culture; photo by Jason Flakes

and associated donated or loaned objects, resulting in deeply emotive exhibitions. The personality and family history of each visitor will vastly impact how they experience the history galleries. Many visitors will have experienced a range of emotions by the time they exit the history galleries.

The design of the museum is perfectly suited for dealing with emotional, or emotionally drained, visitors. Following the history galleries is the Contemplative Court. ${ }^{3}$ A square room with bronze-colored walls is lit up by a giant round skylight. From the edges of the skylight, a circular waterfall drips down into a large square fountain. Visitors can sit here, look at the water and the light, listen to the sound of the fountain, and reflect upon empowering quotes by Martin Luther King Jr., Nelson Mandela, Frances Ellen Watkins Harper, and Sam Cooke. It is intended to be a space for pure emotion: for grief, for reflection, for resilience, for relief, for respite, and for release. Here, visitors know that they can cry, sing, or sit in silence freely and for as long as they wish.

The design of the NMAAHC shows deep empathy with its visitors. The Contemplative Court is given a central place and a space of importance. It catches and embraces visitors after they have journeyed through the history 
exhibitions whose route is over a mile long. This large space for emotion plays a significant role in the visitors' experience of the exhibition route and is more powerful than a small reflective nook or a seat to rest weary legs in a crowded exhibition hall. It is similar to reflective spaces in memorial museums, such as Holocaust museums or war memorials, but its moving water adds a spiritual and cleansing dimension. It helps visitors process historical grief before walking on to celebrate the contemporary.

\section{Museo Tula | Lagun, Curaçao}

Museo Tula (MT) was founded in 2007 and sits towards the Northwestern point of the Caribbean island of Curaçao. It is located on a former plantation estate and the main museum building is in the former great house (landhuis). The estate buildings were renovated for the purpose of the museum, whereas the lands of the estate are minimally maintained. The grounds along the rugged coastline are incorporated as a natural resource and a visit to the museum can be combined with an extensive walking tour through the gardens and wider landscape. The estate as a whole forms an ecomuseum. ${ }^{4}$

The mission of MT is to represent the local Afro-Caribbean community and this community is both its main target audience and its staff. In part, the museum focuses on Tula's uprising (1795) and other local revolts by enslaved persons. Other parts of the museum are dedicated to various aspects of Afro-Caribbean heritage, whether before or after emancipation: music, food, midwifery, clothing, and rituals surrounding birth and death. Throughout all of the museum, the underlying theme is resilience and resistance. For instance, musical instruments are paired with engravings showing celebrating, dancing enslaved persons and Dutch colonial proclamations forbidding the playing of drums or dancing among the enslaved.

Especially within this former plantation estate, MT undertakes strong acts of decolonization. Afro-Caribbean community members work here as tour guides to tell Tula's history and the history of their community from their own perspectives. 5 They are able to bring in personal histories to their tours. These community members are also vital for infusing the museum with intangible heritages. Some are hired to work in the museum's kitchen to prepare Afro-Caribbean meals and snacks; visitors can choose to add a warm lunch to their museum visit when they purchase their entrance ticket. 
Figure 4.2 The display on Afro-Caribbean literature includes a Papiamentu poem by Pierre Lauffer, beginning with the lines "Papiamentu indominable I Lenga di mi mama"

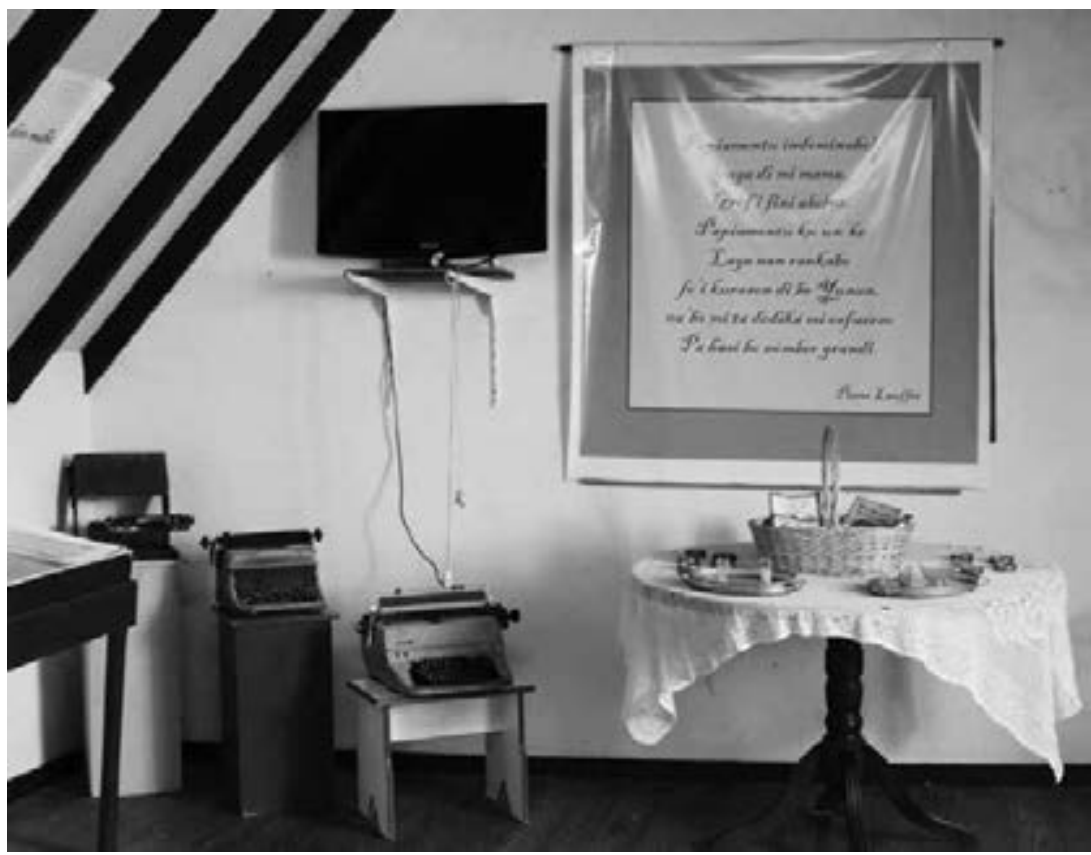

Museo Tula; photo by Csilla E. Ariese, 2014

Thus, the formerly colonized have retaken the entire plantation estate with their own cultural heritage: music, food, performances, histories, and objects.

An important aspect of MT's decolonization has been language. Indeed, the historical roots of post-colonial theories were in the field of literature. Furthermore, the field of decolonization has been impacted by the influential work by writer Ngũgĩ wa Thiong'o titled Decolonising the Mind. ${ }^{6}$ Language, he argues, is both a means of communication and a carrier of culture. It defines us and others, it transmits images of the world and reality. Essentially, the language we use shapes our culture, our identities, and how we see and understand the world around us. As such, the choice of language(s) used in a museum is far from a neutral decision.

Museo Tula uses Papiamentu as its main language throughout the museum and its exhibitions. Papiamentu is a creole language which probably developed around the $17^{\text {th }}$ century. At its roots, it is a mixture of Portuguese 
Figure 4.3 Decolonize language

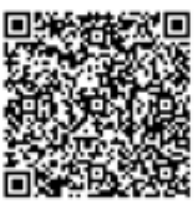

Artwork by Elwing Sương Gonzalez aka @elwingbling, 14 July 2020

and West African, with later influences from Dutch, English, and Spanish. It is presumed that the language was developed by enslaved persons working on plantations in Curaçao as a means of communication. It was also used by Sephardic Jewish colonizers, resulting in some of the earliest written documents in Papiamentu. Despite the Dutch colonizers' introduction of Dutch language education, thanks to strong and continued resilience, Papiamentu remained the main (spoken) language. After centuries of attempts to 'eradicate' this creole language by the colonizers, it was finally recognized as an official language in 2007.7 Museo Tula's decision to use Papiamentu as its main language is a decolonial act which shows empathy for a community whose language has been repressed for centuries. It allows that community to feel at home in the museum.

\section{POLIN Museum of the History of Polish Jews | Warsaw, Poland}

Set on the site of the former Jewish Ghetto of Warsaw, the POLINMuseum of the History of Polish Jews (POLIN) was opened to the public in 2013. The museum is run through a public-private partnership between the Association of the Jewish Historical Institute, the city of Warsaw, and the Ministry of Culture and National Heritage. In recent years, this partnership has revealed political clashes, particularly in appointing new directors of the museum.

The aim of the museum is to show the 1,000-year history of Jewish life in Poland, demonstrating on the one hand that Polish history is Jewish history, and on the other hand that Jewish history is Polish history. The museum promotes "the ideas of openness, tolerance and truth" and is a place for dialogue for "those who are ready to face the stereotypes and oppose xenophobia and nationalistic prejudices that threaten today's societies."

7 Papiamento was previously recognized in Aruba in 2003.

8 As quoted from the POLIN Museum website. Available at https://www.polin.pl/en/aboutmuseum (accessed 1 April 2021). 
While the museum focuses on the culture and history of a religious community, it is in many ways overtly political. For instance, its temporary exhibition Estranged: March '68 and Its Aftermath (2018) presented slogans from the anti-Semitic campaign of ' 68 together with quotes by contemporary Polish political leaders - resulting in a conflict between the museum and politicians in the media. In today's political landscape in Poland, the museum frequently finds itself having to fight for its mission to promote tolerance.

A significant amount of the museum's visitors come from abroad. In part, these are Jewish visitors whose family histories are related to the Warsaw Ghetto, or Polish Jews who have (been forced to) emigrated. The museum, and the memorial commemorating the Warsaw Ghetto Uprising of 1943 just outside, have become a site of pilgrimage.

The core exhibition is roughly chronologically structured and narratively follows 1,000 years of Jewish life, beginning with the first Jewish settlers in Poland in the 1oth century. Many of these early galleries contain replicas and aim to show traditional cultures, constructions, and ways of life. They also tell family biographies. Emotionally, the most affective galleries are those dedicated to the Holocaust and the Postwar Years, including pogroms and large-scale emigration due to a state-sponsored anti-Semitic campaign.

In the Holocaust gallery, many exhibition design techniques are used to ensure that the content of the exhibition is emotionally powerful and effective. For instance, the gallery is designed with a footbridge between two sets of stairs, overlooking a vibrant street. This design mimics the layout of the Warsaw Ghetto with a footbridge over Chłodna Street (an Aryan street) dividing the small and large Ghettos. Photographs of this footbridge have become iconic symbols of the Holocaust in occupied Poland. Furthermore, the exhibition contains many moving images, such as videos of life in the Ghetto, and audio fragments, which are particularly powerful tools for conveying personal stories. Quotes - both from survivors and those who perished or were murdered - provide strong emotional insights into life in the Ghetto. A long wall with endlessly many chalked numbers representing the people deported per day (July-September 1942) brings home the incomprehensible loss of life together with hastily written notes to neighbors or family members.

The core exhibition abounds in photographs. Yet, with very few exceptions, there are no photographs of dead persons. Only a few photos are shown in which the dead are entirely anonymous and their heads and faces are not visible. As a curator of POLIN explained, this was a deliberate act of empathy: "it is not that we do not want people [visitors] to feel hurt. We do 
not want to humiliate victims again." 9 Thus, the core exhibition succeeds to be highly emotive - and to offer visitors the space to deal with these emotions - but also manages to leave victims' dignity intact.

\section{Tate Modern | London, UK}

The Tate Modern is one of four Tate museums, sharing a collection of nearly 70,000 artworks. The other three sites are Tate Britain, Tate Liverpool, and Tate St Ives. The collections are partially British art from 1500 until today and partially international modern and contemporary art. The first Tate museum opened to the public in 1897. Tate Modern focuses on international modern and contemporary art and was opened in 200o. It is housed in a former power station, whose unique architecture - and especially its famous turbine hall - impact the visiting experience and the possibilities for exhibitions and programs. The turbine hall is used for large-scale art installations, but also provides a grand open space for school groups to engage in activities or lunch in parallel. The exhibitions, located over several floors in two connected towers, encourage visitors to pick and choose which exhibitions to visit without a set path.

As with other national galleries and museums in the UK, Tate Modern charges no admission fee for its permanent exhibitions. It is vastly popular, attracting roughly 6 million visitors annually. Naturally, these visitors do not all share the same pre-existing knowledge of contemporary art. While some may be highly knowledgeable in the field and very familiar with how to 'read' contemporary art exhibitions, for others it might be their first time in such a museum. Art museums, with their white cube aesthetic and often minimal object descriptions, can be particularly daunting for inexperienced visitors. What should they be looking at or looking for? In such a situation, a visitor may feel alienated and as if they do not belong in that space.

Tate Modern offers an entry exhibition, called Start, particularly for visitors who may appreciate suggestions on how to visit an art exhibition and how to experience artworks. Curated by Ann Coxon and Tate Learning, the team has been empathic to ensure that the tone of the exhibition and its labels are not condescending. Instead, Start aims at disalienation. It offers tips to guide visitors through the rest of the museum, such as: don't feel like you have to see everything today; you don't have to like all the art; think about your first reaction to the work; and so forth. It also highlights words that are typical museum terms, but which may not be familiar to 
Figure 4.4 Start introductory panel

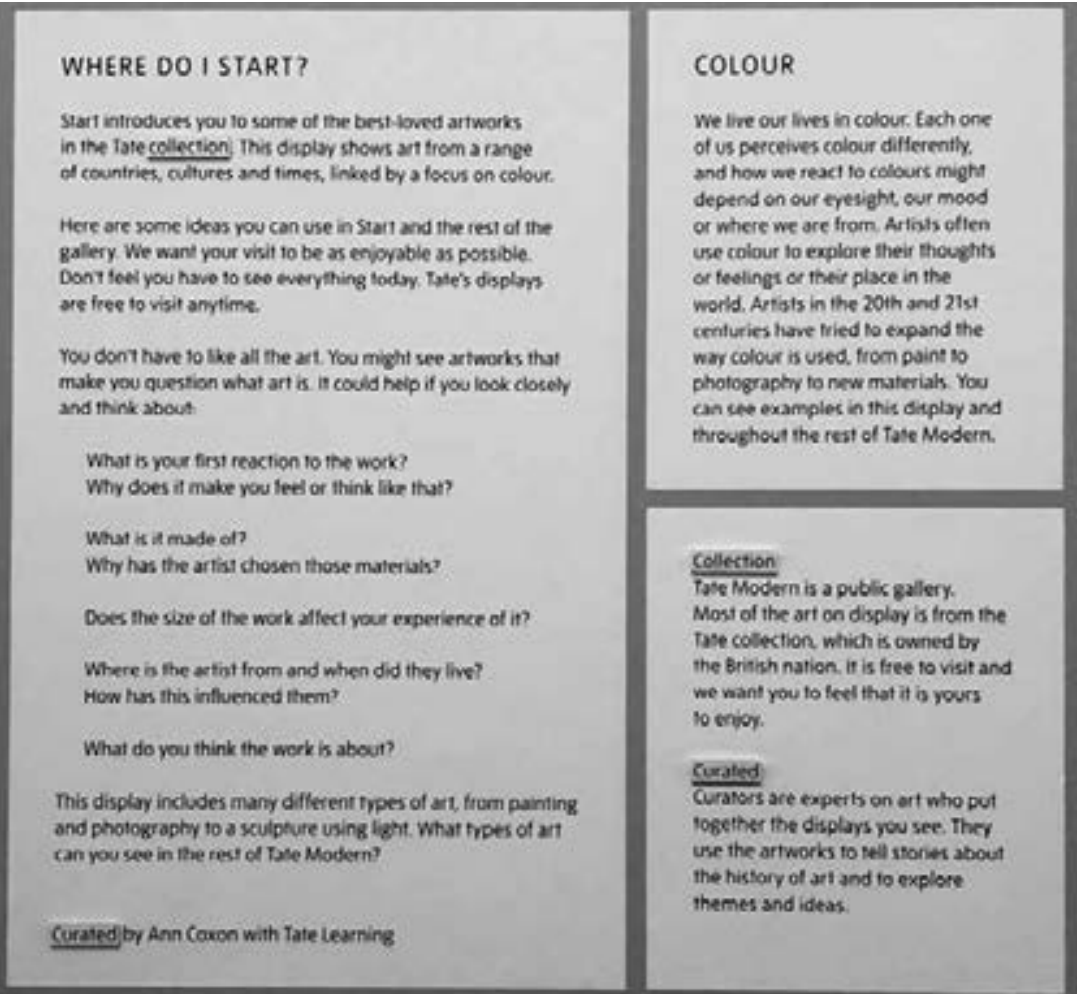

Tate Modern; photo by Csilla E. Ariese, 2019

inexperienced visitors, and then provides short definitions. The introductory panel is phrased predominantly in questions, allowing the reader to come to their own answers. The theme of the exhibition is color, a concept which is openly explored in all the artworks, allowing the spectator to grasp from the beginning what links all the works together.

The traditional object panels accompanying each artwork are expanded. An adjacent panel explains what types of information are on the object label, thus showing you where to look on the label for the name of the artist or where to find the reason for the artwork being in this exhibition. Furthermore, it contains a quote by the artist that relates to the theme color, making overtly clear connections between the artist, the artwork, and the exhibition. As such, Start is an empathic beginning of a path through Tate Modern, hopefully leading people to feel welcome, prepared, and knowledgeable enough for their visit. 


\section{Further reading}

Memorial Museums: The Global Rush to Commemorate Atrocities | Paul Williams 2007

Nuts and Bolts: Developing a Toolkit for Emotion in Museums | Linda Norris and Rainey Tisdale $\mid 2017$

Words Matter: An Unfinished Guide to Word Choices in the Cultural Sector | edited by Wayne Modest and Robin Lelijveld | 2018

\section{Further examples}

The Museum of Broken Relationships

Zagreb, Croatia (created 20o6)

"The Museum of Broken Relationships is a physical and virtual public space created with the sole purpose of treasuring and sharing your heartbreak stories and symbolic possessions. It is a museum about you, about us, about the ways we love and lose. At its core, the museum is an ever-growing collection of items, each a memento of a relationship past, accompanied by a personal, yet anonymous story of its contributor. Unlike 'destructive' self-help instructions for recovery from grief and loss, the museum offers the chance to overcome an emotional collapse through creativity - by contributing to its universal collection." ${ }^{\text {10 }}$

BITTER Chocolate Stories exhibition at the Tropenmuseum

Amsterdam, the Netherlands (2019)

"Stories from children about cocoa plantations in Ghana and the Ivory Coast. More than 2 million child labourers work on cocoa plantations in Ghana and the Ivory Coast, and tens of thousands of children are victims of trafficking and forced labour in cocoa production. Who are these children and why do they work there? Six of them tell their story in BITTER Chocolate Stories: Valerie, Mohamed, Catherine, Bassirou, Sarata and Issaka. Because of these children, we - the chocolate consumers thousands of miles away - can eat the chocolate that we enjoy so much."11

10 As quoted from the Museum of Broken Relationships website. Available at https://brokenships. com/explore?open=about-museum (accessed 1 April 2021).

11 As quoted from the Tropenmuseum website. Available at https://www.tropenmuseum.nl/ en/whats-on/exhibitions/bitter-chocolate-stories (accessed 1 April 2021). 
Emotion networking method by the Reinwardt Academy and Imagine IC Amsterdam, the Netherlands (since 2011)

"Fascinated by the often-clashing emotions about museum collections, monuments, traditions and everyday cultural repertoires, they coined the term emotion networking. As a noun, emotion networks stand for the capricious constellations that form around heritage in everyday life. But emotion networking is also a verb. It is an exercise that provides insight into the complex interplay of emotions and interests surrounding heritage. The purpose of emotion networking is that participants see the mutual relationships change and thereby become (more) aware of the complex dynamics surrounding heritage. [...] The method is being further developed, for, with and in practice." ${ }^{12}$

With our thanks for this suggestion to Daniëlle Kuijten.

\section{Taking Care project lead by the Weltmuseum Wien}

Europe (2019-2023)

"The project TAKING CARE - Ethnographic and World Cultures Museums as Spaces of Care started on October 1, 2019 and places Ethnographic and World Cultures Museums at the centre [...] The project is organised around a set of interlinked themes, along a scale that starts from the museum as a site for care, opening towards thinking about the caring for the planet and its future, then on questions related to the unequal sharing of heritage resources and restitution. [...] Rather than think of the museum as spaces to come in from the worrisome street to see beauty, or to escape reality there is increasing demand for the museum to be that site where contestation can be engaged with in 'safe spaces'. [...] the central question [is] how ethnographic and world cultures museums can be activated to address the twinned concerns of planetary precarity and the precarity of plural societies. ${ }^{m 3}$

With our thanks for this suggestion to Wayne Modest.

12 As quoted from the Reinwardt Academy website. Available at https://www.reinwardt.ahk. $\mathrm{nl} / \mathrm{en} /$ research-group-cultural-heritage/emotion-networking/ (accessed 1 November 2020). 13 As quoted from the Taking Care website. Available at https://takingcareproject.eu/about (accessed 1 April 2021). 


\section{References}

Ariese-Vandemeulebroucke, Csilla E. 2018. The Social Museum in the Caribbean: Grassroots Heritage Initiatives and Community Engagement. Leiden: Sidestone Press.

de Varine, Hugues. 1978. "L'Écomusée." Gazette 11.2: 28-40.

Keyes, Allison. 2017. "In This Quiet Space for Contemplation, a Fountain Rains Down Calming Waters." Smithsonian Magazine [exhibition review], 21 September 2017. Available at https://www.smithsonianmag.com/smithsonian-institution/ quiet-space-contemplation-fountain-rains-down-calming-waters-180964981/ (accessed 1 April 2021).

Modest, Wayne, and Lelijveld, Robin, eds. 2018. Words Matter: An Unfinished Guide to Word Choices in the Cultural Sector. Work in Progress series. Wormerveer: Tropenmuseum, Afrika Museum, Museum Volkenkunde and Wereldmuseum. Ngũgĩ wa Thiong'o. [1986] 2004. Decolonising the Mind: The Politics of Language in African Literature. Nairobi: East African Educational Publishers.

Norris, Linda, and Tisdale, Rainey. 2017. "Nuts and Bolts: Developing a Toolkit for Emotion in Museums." Exhibition 2017 (Spring): 100-108.

Wiginton, Christina, and Holman Conwill, Kinshasha. 2016. The National Museum of African American History \& Culture: A Souvenir Book. Washington, D.C.: Smithsonian Books.

Williams, Paul. 2007. Memorial Museums: The Global Rush to Commemorate Atrocities. Oxford and New York: Berg. 